\title{
Editorial
}

\section{Não devemos andar para trás!}

\author{
Por Marcel Bursztyn, Melissa Curi, Gabriela Litre,
} Carlos Hiroo Saito

Já se passou quase meio século, desde as primeiras reuniões preparatórias para a Conferência das Nações Unidas sobre Meio Ambiente Humano, que teve lugar em Estocolmo, em 1972. Aquele evento é considerado um marco fundador do despertar mundial para os desafios ambientais que afetam todo o Planeta.

No ano seguinte, a criação da Secretaria Especial do Meio Ambiente - SEMA foi um importante passo na institucionalização da questão ambiental como responsabilidade do Governo Federal no Brasil. Depois, a Lei 6.938, que instituiu a Política Nacional do Meio Ambiente, em 1981, serviu como marco regulatório para a proteção ambiental. Já no final daquela década, foi criado o Instituto Brasileiro do Meio Ambiente e Recursos Naturais Renováveis - IBAMA. Em seguida, a proteção ambiental adquiriu o status de ministério, seguindo uma tendência internacional. Outros instrumentos relevantes foram estabelecidos: as políticas de águas, de florestas, de resíduos sólidos, o combate ao desmatamento, o enfrentamento das causas antropogênicas das mudanças climáticas, dentre outros.

Todos representaram passos à frente, na busca de um meio ambiente saudável, que, desde a Constituição de 1988, passou a ser considerado um direito da cidadania. Cada um desses passos foi resultado de ampla mobilização de forças políticas, com negociações, muitas vezes difíceis, entre representantes de uma complexa teia de interesses e visões. Depois de tantos avanços institucionais, de relevantes pactos internacionais, de notáveis evoluções científicas (que permitem a identificação de riscos e orientam estratégias de mitigação e de adaptação), era de se esperar que a esfera política, em escala mundial, se apoiasse nesses fundamentos para adotar medidas compatíveis.

No entanto, e paradoxalmente, o momento atual inspira pessimismo. Uma maré conservadora tem reivindicado retrocessos, neutralizando avanços institucionais e duvidando de certezas científicas, em nome de interesses econômicos imediatistas e de visões por vezes obscurantistas. Em pleno século XXI, emergem dogmas comparáveis aos que condenaram Galileu Galilei pela tese do heliocentrismo, há quatro séculos.

Quando o jornal inglês The Guardian noticiou, em 15/11/2018, que o Ministro das Relações Exteriores do Brasil, indicado pelo novo Governo, defende que as mudanças climáticas são uma trama marxista ${ }^{1}$, o paralelismo com a história dos tempos de Galileu levanta preocupações quanto ao comportamento do Governo eleito sobre o Acordo de Paris e a compreensão das sinergias entre políticas públicas e os impactos sobre o clima e o meio ambiente. Mais ainda, uma pré-concepção obscurantista pode erigir uma barreira ao desenvolvimento da ciência, pela simples crença de que pesquisas em um determinado campo da ciência não representariam, sob esse ponto de vista, efetivamente ciência. O que vai ser, por exemplo, da Rede Brasileira de Pesquisas sobre Mudanças Climáticas Globais (Rede CLIMA) nesse contexto? Deveremos investir em pesquisas sobre a relação entre a manutenção da floresta Amazônica, os Low Level Jets e as chuvas no Pantanal e na bacia hidrográfica do Prata?

1 https://www.theguardian.com/world/2018/nov/15/brazil-foreign-minister-ernesto-araujo-climate-change-marxist-plot. 
Em editoriais anteriores, Sustentabilidade em Debate chamou a atenção para retrocessos nas políticas ambientais: sobre o ceticismo climático de Trump (vol. 8, n. 2, 2017) e ao disciplinamento do uso de agrotóxicos no País (vol. 9, n. 2, 2018).

Agora, no Brasil, nuvens carregadas pairam sobre as políticas ambientais. Houve muita incerteza sobre a sobrevivência do Ministério do Meio Ambiente, principalmente sobre o seu papel. Lobbies ruralistas avançam sobre a possibilidade efetiva de regulação da proteção florestal, dos direitos das populações indígenas e quilombolas, do cumprimentos dos compromissos internacionais voluntários em relação à mudança do clima. É responsabilidade do mundo acadêmico alertar sobre os riscos imanentes aos anunciados passos para trás que estão na agenda política.

Ex-ministros de Meio Ambiente de diversas gestões governamentais, desde 1992, publicaram um alerta dessa natureza, na coluna Opinião do jornal Folha de São Paulo, em 22/10/20182. Com o título "Não podemos desembarcar do mundo: É essencial ao país manter-se no Acordo de Paris", a matéria revela o mesmo temor frente às ameaças de retrocesso.

Meio século de construção institucional, de avanços científicos e de formação de pessoal especializado não podem ser descartados. Não é prudente! Na democracia, a alternância do poder é um fato normal e previsível. Mas o desmantelamento de estruturas institucionais, que pode ser implementado em curto prazo, provocarão efeitos que vão demandar muito tempo para serem reparados. No caso, as consequências não são apenas formais; são, principalmente, ameaças à própria sustentabilidade do desenvolvimento que se quer para o Brasil, em todas as suas dimensões: econômica, social, cultural e ecológica.

SeD assume sua responsabilidade em lançar a advertência: não devemos andar para trás!

Na presente edição (vol. 9, n. 3, 2018), Sustentabilidade em Debate já incorpora os primeiros passos no sentido da sua estratégia de internacionalização. Dentre os onze artigos da seção Varia que estamos publicando, três já estão em inglês e um outro em francês. Com isso, visamos que os trabalhos publicados na revista sejam acessíveis em todo o mundo, por um público que não necessariamente leia em português.

Essa é uma tendência dos principais periódicos científicos, aos quais nos juntamos, graças ao apoio que recebemos da Fundação de Apoio à Pesquisa do Distrito Federal (FAP-DF). Hoje, temos aproximadamente $15 \%$ de nossos leitores fora do Brasil. A meta é que esse número cresça gradativamente. Para isso, esperamos contar com a compreensão dos autores que nos prestigiam com a submissão de seus artigos. Ao longo de 2019, passaremos a publicar progressivamente em inglês, até atingirmos 100\% dos textos.

Ainda sobre as novas tendênicas de $S e D$ já para 2019, vale mencionar que, a partir de janeiro, passaremos a cobrar uma taxa de submissão dos artigos, cujo valor e outras informações estarão disponíveis no site da revista, em "Diretrizes para Autores". Estamos cientes das dificuldades da comunidade científica em termos de recursos disponíveis para custear publicações de artigos, mas não temos como evitar esta cobrança, já que não dispomos de meios para cobrir os custos operacionais de SeD.

Na seção Varia, o primeiro artigo, das autoras Nancy Ramacciotti de Oliveira Monteiro e Debora Santos Silva, com o título "Percepções do ambiente, condições psicológicas e de qualidade de vida em habitantes de ocupações irregulares de área de manguezais na Baixada Santista, SP, Brasil", faz um estudo sobre a percepção ambiental dos moradores da referida área de manguezal, utilizando instrumentos específicos de coleta de dados para avaliação da qualidade de vida, tais como o WHOQOL-bref (World Health Organization Quality of life) e o ARS (Adult Self-Report for ages 18-59).

Os próximos dois artigos, seguindo a mesma linha de percepção do ambiente, apresentam uma análise sobre a concepção e a modificação da paisagem. $\mathrm{O}$ artigo "A paisagem percebida no pulsar do Complexo Ambiental Sacaí, Baixo rio Branco, Roraima, Brasil", dos autores Thiago Costa Alves, Sandra Noda e Juliane de Souza, debruça-se sobre o agroecossitema amazônico. Já o artigo "Geographic reconstruction of a Central-West brazilian landscape devastated during the first half of the 20th century: Mato Grosso de Goiás" ("Reconstituição geográfica de uma paisagem devastada durante a primeira metade do século XX na região Centro-Oeste do Brasil: o Mato Grosso de Goiás"), dos autores Carlos Christian Della Giustina, Sandro Dutra e Silva e Eder Martins, apresenta uma reconstituição geográfica de uma área do Cerrado brasileiro.

2 https://www1.folha.uol.com.br/opiniao/2018/10/nao-podemos-desembarcar-do-mundo.shtml 
Os autores Wagner de Deus Mateus, Maria Inês Higuchi, no artigo "Processos estruturais do manejo e conservação da fauna silvestre em risco de extinção: casos amazônicos", analisam a estrutura e os processos envolvidos na conservação e manejo de duas espécies da fauna silvestre amazônica em risco de extinção, o Gavião-Real (Harpia harpyja) e o tracajá (Podocnemis unifilis).

No artigo "Extração de madeira e organização social no PDS Virola-Jatobá, Anapu, Pará: Percepções e discursos contrastantes em um assentamento ambientalmente diferenciado", os autores Helder Assunção e Roberto Porro levantam a percepção dos assentados do Projeto de Desenvolvimento Sustentável (PDS) da área estudada em relação à extração madeireira e os benefícios derivados da atividade.

Com foco em saúde e meio ambiente, o artigo "Utilização de macroinvertebrados bêntonicos como bioindicadores em córrego urbano de Conceição do Araguaia-PA", dos autores Maria Elisa Queiroz, Alexandre Schäffer, Ana Carolyna Villela, Danilo Martins e Paulo Henrique da Silva, faz uma avaliação das condições ambientais e de qualidade da água de um córrego urbano no estado do Pará, por meio da captura dos referidos organismos e posterior classificação pelo índice Biological Monitoring Working Party Score System (BMWP).

Com uma temática parecida, mas com outra perspectiva, o artigo "Représentations sociales chrétiennes, santé et environnement en Amazonie brésilienne" ("Representações sociais cristãs, saúde e meio ambiente na Amazônia brasileira"), dos autores Natacha Lecours, Johanne Sant-Chareles, Frédéric Mertense Marc Lucotte, busca compreender por que alguns grupos religiosos estão mais envolvidos do que outros em questões que conectam o meio ambiente e a saúde. Para tanto, o estudo considerou representações sociais de grupos católicos e evangélicos de comunidades ribeirinhas na Amazônia brasileira.

As autoras Marta Aparecida de Moura e Alba Regina Arana, no artigo "Fragmentação ambiental no Parque Estadual do Morro do Diabo em Teorodo Sampaio, SP, Brasil", por meio de uma pesquisa quali-quantitativa, fazem uma análise histórica das políticas públicas que determinaram a formação do território no município e os impactos ambientais causados desde a legalização do PEMD (Parque Estadual do Morro do Diabo), de 1941 a 2006.

O artigo "A atividade cemiterial nos municípios brasileiros: impactos ambientais, ordenamento jurídico e perspectivas futuras", dos autores Camila Baum e Valter Becegato, apresenta os impactos ambientais decorrentes da atividade cemiterial tradicional e as questões jurídicas que as envolvem, além de apontar tendências futuras para a destinação dos corpos.

Fechando a edição de dezembro, os dois últimos artigos tratam de resíduos sólidos. O artigo "Economic valuation in selective solid waste collection" ("Valoração econômica da coleta seletiva de resíduos sólidos"), dos autores Anny Kariny Feitosa, Júlia Elisabete Barden, Odorico Konrad e Manuel Arlindo Matos, apresenta uma estimativa da valoração econômica da coleta seletiva na cidade de Juazeiro do Norte, por meio da aplicação do Método de Valoração Contingente. E, o artigo "Substituição de agregados minerais por resíduos de concreto na fabricação de pavimento asfáltico", dos autores Gabriela Garcia, Marliton Barreto e Flávio Crispim, faz uma análise da viabilidade técnica do emprego de resíduos de blocos de concreto em substituição aos agregados minerais em pavimentação asfáltica.

Desejamos uma ótima leitura e um feliz Ano Novo!

\section{A equipe Editorial.}

